\title{
A Case of Renal Medullary Cystic Disease with Proximal Tubular Dysfunction
}

\author{
Toshiro Fujita, MD, Masaru Itakura, MD, Hideo Mitamura, MD \\ *Masayuki Nomura, MD, *Masakatsu Shibagaki, MD, *Koshiro Watanabe, MD \\ *Toshio Fukui, MD, **Hiroshi SaKaguchi, MD
}

\begin{abstract}
A 50-year-old man with sporadic renal medullary cystic disease associated with moderate renal failure, severe anemia, dehydration and osteodystrophy, and without edema, hypertension or remarkable urine sediment was studied. Hyperchloremic acidosis and hypokalemia were found in this patient, which could be explained as a consequence of proximal renal tubular acidosis, since, during the normalization of plasma bicarbonate level by the adminstration of sodium bicarbonate, urinary potassium excretion was increased and urinary pH was further increased to 8.1. In addition, he had generalized aminoaciduria and increased clearance of phosphate and uric acid. Particularly the lysozyme clearance $\left(\mathrm{C}_{1 \mathrm{y}} / \mathrm{C}_{\mathrm{cr}}\right)$ in this patient was significantly higher than in patients with chronic glomerunephritis, and equal to the value of Fanconi's syndrome. The presence of salt-wasting, hyperchloremic metabolic adidosis, aminoaciduria, hyperuricosuria and "tubular proteinuria", suggests that the patient with medullary cystic disease is associated with multiple proximal tubular dysfunction. The finding of renal biopsy is presented which suggests that this disorder represents a toxic nephropathy.
\end{abstract}

Key Words: Toxic nephropathy, Renal tubular acidosis, Tubular proteinuria, Aminoaciduria, Osteodystrophy.

Medullary cystic disease is a term used to describe a renal disorder characterized by the insidious onset of uremia and severe anemia without edema, hypertension or remarkable urine sediment ${ }^{1,2)}$. In Japan, there have been reported very few cases of this disorder ${ }^{16)}$. In general, there occurs the clinically important phenomenon of renal salt wasting and distal tubular dysfunction, but notably absent is a proximal tubular dysfunction ${ }^{3,4}$. We have encountered a patient with medullary cystic disease associated with hyperchloremic metabolic acidosis, hypokalemia, hyperuricosuria, and "tubular proteinuria", possibly as a consequence of proximal renal tubular dysfunction. Moreover, we describe that this disorder is clinically and histologically similar to a toxic nephropathy

\section{CASE REPORT}

A 50 year old Japanese man was first admitted to Kawasaki City Ida Hospital for the investigation of his anemia and renal failure in March, 1974. At age 40 he was asymptomatic when first seen by a physician for evaluation of proteinuria and glycosuria. For the previous three years he had been unwell with increasing pallor, polydipsia and polyuria. There had been no episodes of loin pain, edema hematuria, or hypertension. None of his family were known to have renal disease. Physical examination revealed a chronically ill man

From the Department of Internal Medicine, Schoo of Medicine Keio University, Tokyo.

*The Municipal Ida Hospital, City of Kawasaki, Kanagawa.

**The Department of Pathology School of Medicine, Keio University, Tokyo.

Received for publication December 6, 1977.

Request reprints to: Dr Toshiro Fujita, Institute of Glinical Medicine. The Uriversity of Tsukuba, Niihari-gun. Ibaraki-ken, 300-31, JAPAN. 
with poor turgor of the skin and pronounced pallor of mucous membranes. He was $170 \mathrm{~cm}$ tall and weighed $54 \mathrm{Kg}$. Blood pressure, with the patient in the supine position, was $94 / 60 \mathrm{mmHg}$; upon standing it quickly decreased to $80 / 50 \mathrm{mmHg}$ without symptoms. A grade 2 systolic murmur was heard at the apical and the left sternal border areas. There was neither hepatosplenomegaly nor lymphadenopathy. Fundoscopic examination showed arteriolar narrowing and tortuosity, comparable to a grade I of Keith-Wagner's classification. Laboratory examination showed a red cell count of $267 \times 10^{4} / \mathrm{mm}^{3}$, hemoglobin level of $9.0 \mathrm{~g} /$ $100 \mathrm{ml}$, white blood cell count of $4,600 / \mathrm{mm}^{3}$ and platelets $246,000 / \mathrm{mm}^{3}$. Bone marror showed reduced erythropoiesis. Serum sodium was $137 \mathrm{mEq} / 1$, chloride $118 \mathrm{mEq} / 1$, potassium $2.8 \mathrm{mEq} / 1$ and bicarbonate $17.4 \mathrm{mEq} / 1$. Serum creatinine was $3.2 \mathrm{mg} /$ $100 \mathrm{ml}$, blood urea nitrogen $72.4 \mathrm{mg} / 100 \mathrm{ml}$, calcium $7.8 \mathrm{mg} / 100 \mathrm{ml}$, phosphorus $2.2 \mathrm{mg} /$ $100 \mathrm{ml}$, uric acid $1.5 \mathrm{mg} / 100 \mathrm{ml}$, fasting blood sugar $92 \mathrm{mg} / 100 \mathrm{ml}$, iron $102 \mu \mathrm{g} / 100 \mathrm{ml}$, and total protein was $7.4 \mathrm{~g} / 100 \mathrm{ml}$ with $4.6 \mathrm{~g} /$ $100 \mathrm{ml}$ of albumin. Urine volume was 2.0 to 3.5 liter, daily, and $\mathrm{pH}$ ranged between 6. 0 and 7.0. Urinalysis revealed a fixed specific gravity of 1.008 to 1.010 , + proteinuria, Hglycosuria, and a normal sediment. Endogenous creatinine clearance was 28.8 and $32.2 \mathrm{ml} / \mathrm{min} / 1.48 \mathrm{~m}^{2}$. The fractional uric acid clearance $\left(\mathrm{C}_{\mathrm{UA}} / \mathrm{C}_{\mathrm{Cr}}\right)$ was increased 1.2 (normal: 0.05-0.20). As shown in Fig. 1, the fractional lysozyme clearance $\left(\mathrm{C}_{\mathrm{Ly}} / \mathrm{C}_{\mathrm{Cr}}\right)$ in this patient $(9.5 \%)$ was as high as the values of Fanconi's syndrome (8.2 and 10.5\%), compared to those in patients with chronic glomerulonephritis $(0.02 \pm 0.01 \%$, mean $\pm \mathrm{SE})$, suggesting a proteinuria of the "tubular" type. Percent TRP was decreased to 62. Analysis of 24-hour urinary amino acids demonstrated generalized aminoaciduria. Plasma renin activity (radioimmunoassay) was elevated to $8.0 \mathrm{ng} / \mathrm{ml} /$ hour (normal, 0.5-2. $0 \mathrm{ng} / \mathrm{ml}$ / hour) and urinary aldosterone excretion was also increased to $20 \mu \mathrm{g} /$ day (normal,

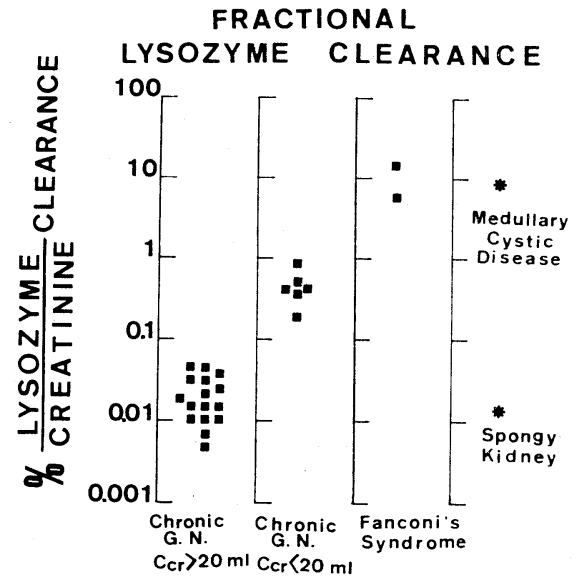

Fig. 1. Fractional lysozyme clearance in 16 patients with chronic glomerulonephritis with various degree of GFR above $20 \mathrm{ml} / \mathrm{min}$, in 6 patients with chronic glomerulonephritis with various degree of GFR below $20 \mathrm{ml} / \mathrm{min}$, in two patients with Fanconi's syndrome, and in this patient with medullary cystic disease. Lysozyme was measured by the lyso-plate method of Osserman et al (17). Fractional lysozyme clearance (\%) was calculated by $100 \mathrm{X}$ lysozyme clearance/ creatinine clearance.

PROXIMAL TUBULAR DYSFUNCTION

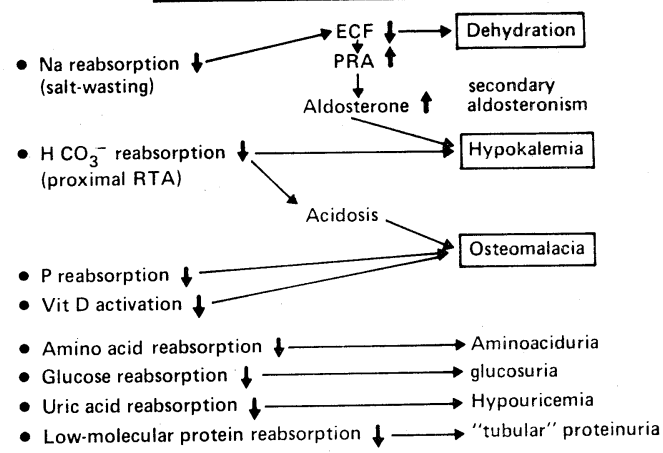

DISTAL TUBULAR DYSFUNCTION

- ADH unresponsiveness —urine concentrating

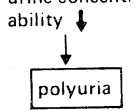

Fig. 2. Tubular Dysfunction in this patient. 
5-10 $\mathrm{g} /$ day). A skeletal survey showed renal osteodystrophy with moderate changes of hyperparathyroidism and osteomalacia, but there was neither calcification on soft tissues nor any bone fracture. There was delayed and incomplete visualization on intravenous pyelogram.

$\mathrm{He}$ was treated with intravenous saline and sodium bicarbonate, and his blood urea nitrogen fell to a minimum of $35 \mathrm{mg} /$ $100 \mathrm{ml}$, but urinary potassium excretion was increased from 62 to $80 \mathrm{mEq} /$ day on a constant diet $120 \mathrm{mEq}$ sodium and $70 \mathrm{mEq}$ potassium, aggravating the hypokalemia with serum potassium level into $2.1 \mathrm{mEq} / 1$, and urinary $\mathrm{pH}$ was increased further to 8. 1, possibly resulting from massive bicarbonaturia. Subsequently, he needed a high fluid intake, a diet restricted in protein, and an oral supplement of sodium bicarbonate and potassium chloride, because of the tendency of "salt-wasting". He was discharged with the temporary diagnosis

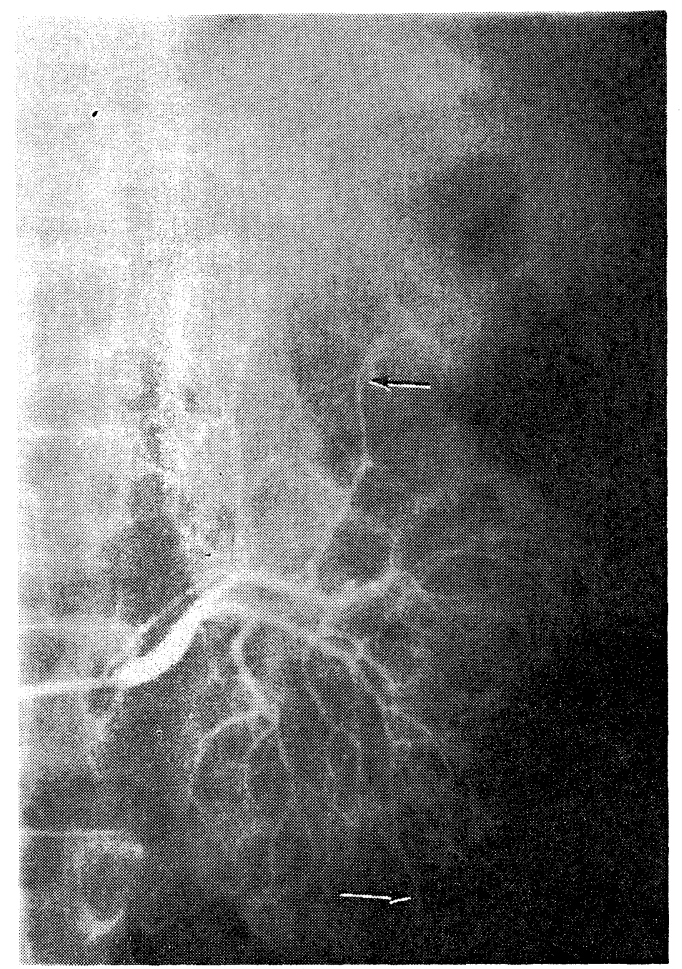

Fig. 3. Left renal arteriogram shows tapering and stretching of the interlobar arteries (arrows). of a "tubular disease" to follow on an Outpatient basis. Fig. 2 shows "tubular dysfunction" seen in this patient.

Over the next two years the BUN level was increased to $130 \mathrm{mg} / 100 \mathrm{ml}$, although he had taken a well-restricted diet, and the patient developed signs and symptoms. of uremia. Chronic hemodialysis was. begun. To clarify the diagnosis of this curious tubular disease, we have investigated the radiogical and histological studies in this patient.

Retrograde pyelogram showed unremarkable changes, although usually there are pelvocalceal defects in polycystic kidney. Renal arteriograms demonstratsd the small kidneys with very thin cortex. During the nephrogram phase, renal cysts could be radiologically identified at the inner cortex and medulla (Fig. 4). The interlobar and arcuate arteries were tapered and stretched by these large cysts (Fig. 3)

An open renal biopsy was performed. The kidney was very hard but smooth in the surface. Microscopic examination re-

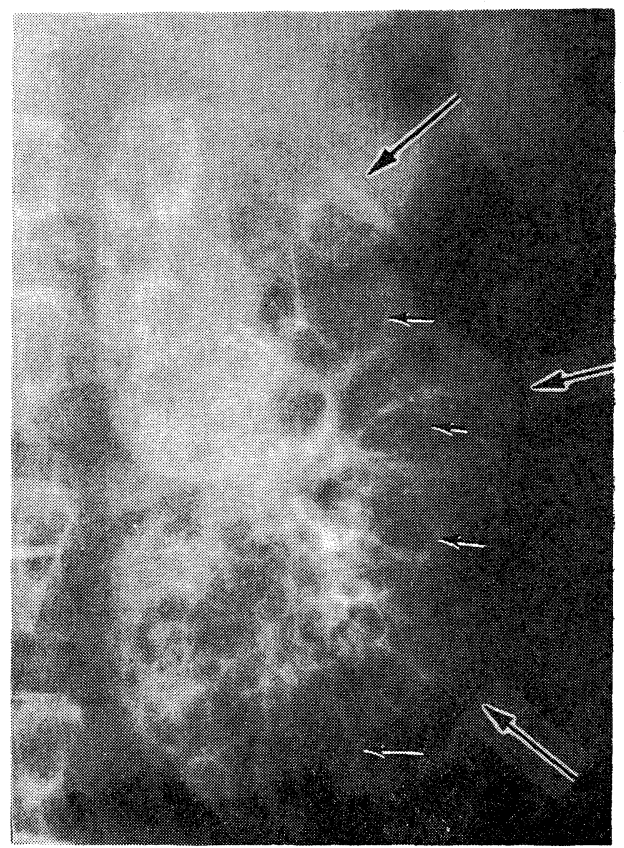

Fig. 4. The nephrogram shows multiple cysts (small arrows), and sparing of the outer cortical margin (large arrows).

Jap J Med Vol 17, No 4 (Oct 1978) 


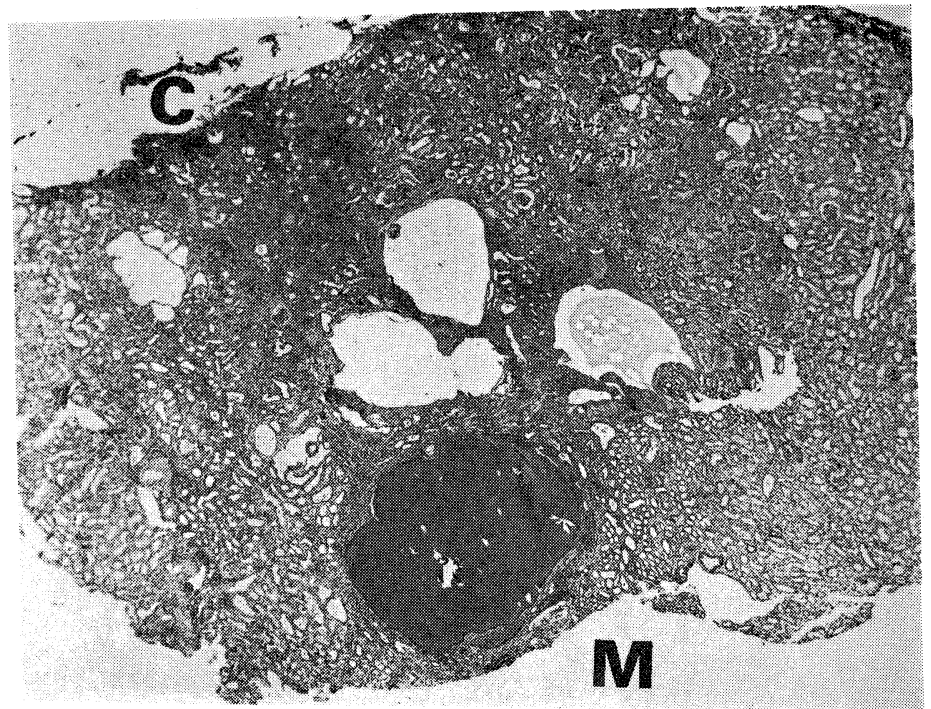

Fig. 5. Microphotograph of the right kidney demonstrates the reduced cortical zone and several cysts at the corticomedullary junction. C: Capsule, M: Medulla (PAS stain, degree of magnification: 15 times).

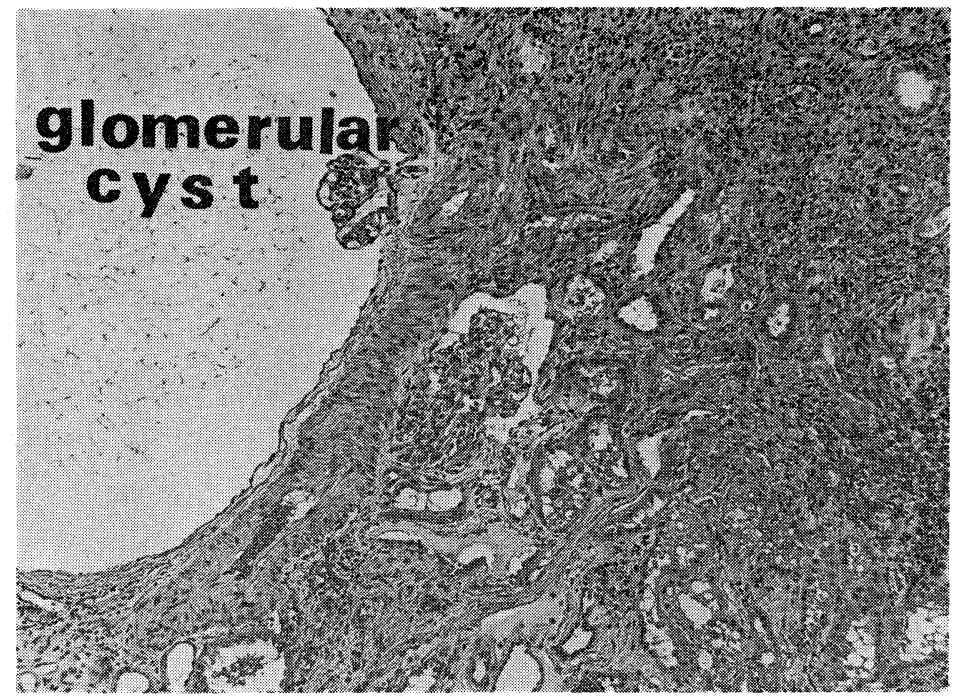

Fig. 6. A Bowman's capsule cyst (Glomerular Cyst) with marked periglomerular fibrosis and interstitial lymphocytic infiltration and fibrosis. (Fiematoxylin-eosin stain, degree of magnification: 96 times).

vealed the reduced cortical zone and several cysts at the corticomedullary junction (Fig. 5). The cysts lined by a regular low cubic epithelium, in most instances single-layered, suggesting dilatation of collecting ducts. There were some cysts composed of the dilated Bowman's capsule (Fig. 6). A ma- jority of the glomeruli were completely hyalinized, but remaining glomeruli showed no abnormality, except for mild hyperplasia of juxtaglomerular apparatus. Severe interstitial fibrosis with lymphocytic infiltration was present. Most of the tubules were almost completely atrophied, and the rest 
were hypertrophied. The basement membrance of some tubules was thickened, forming a collar around the tubules.

\section{DISCUSSION}

Both clinically and histologically, the patient showed typical of medullary cystic disease $^{1-4)}$. Failure to conserve sodium and water, lack of hypertension, and the presence of renal osteodystrophy are all characteristic (2). With the use of renal angiography and renal biopsy, moreover, we obtained such a diagnostic finding as the presence of cysts at the corticomedullary junction.

This disease is a very rare disorder, usually in childhood or adolescence. Some reported cases of medullary cystic disease appeared with sporadic family incidence, suggesting autosomal recessive transmis sion $^{2,3)}$ while others had frequent family involvement consistent with dominant transmission $^{4}$. In Europe, on the other hand, they have used a term "familial juvenile nephronophthisis" which is a disorder of childhood with autosomal recessive genetic transmission, having a similar histological appearance except for occasional absence of $\operatorname{cysts}^{5}$. In 1964, Winberg suggested that juvenile nephronophthisis and medullary cystic disease might be identical $^{6}$. Subsequently, investigators generally have supported his opinion ${ }^{7}$. However, nephronophthisis has been reported in the young, while there has been a patient with medullary cystic disease who survived to fifty-six ${ }^{2)}$. Therefore, a term "medullary cystic disease" seems to be rather suitable for our patient since his age was fifty and his kidney contained numerous cysts.

Medullary cystc disease is one of the renal cystic diseases. Clinically, it is diffi cult to differentiate it from the other cystic diseases such as polycystic kidney and medullary sponge kidney. However it is important to make a diagnosis, since medullary cystic disease has poor prognosis with severe complications such as anemia, dehydration and osteodystrophy, compared to the other two cystic diseases. In table 1 , one can see the characteristic findings for the differential diagnosis between polycystic kidney, medullary sponge kidney, and medullary cystic disease. Polycystic kidney is often associated with hypertension and hematuria, but medully cystic disease usually occurs without hypertension or he-

Table 1. Differnces of Medullary Cystic Disease Against Polycystic Kidney and Medullary Sponge Kidney

\begin{tabular}{|c|c|c|c|}
\hline & \multirow{2}{*}{$\begin{array}{l}\text { Polycystic Kidney } \\
\text { (adult-type) }\end{array}$} & Medullary & Medullary \\
\hline & & Kidney & Disease \\
\hline \multicolumn{4}{|l|}{ Clinical changes } \\
\hline $\begin{array}{l}\text { Hematuria } \\
\text { Hypertension } \\
\text { Nephrolithiasis } \\
\text { Kidney size } \\
\text { Polycystic liver }\end{array}$ & $\begin{array}{c}+ \\
\pm \\
\text { enlarged } \\
+\end{array}$ & $\begin{array}{c} \pm \\
+ \\
\text { normal } \\
-\end{array}$ & $\begin{array}{c}\overline{-} \\
\overline{-} \\
\text { small }\end{array}$ \\
\hline \multicolumn{4}{|l|}{ Renal function } \\
\hline $\begin{array}{l}\text { Renal failure } \\
\text { Hyperchloremic } \\
\text { acidosis } \\
\text { Sodium wasting } \\
\text { Tubular proteinuria }\end{array}$ & $\begin{array}{c}+ \\
+ \text { (proximal) } \\
- \\
-\end{array}$ & $\begin{array}{c}- \\
+(\text { distal }) \\
- \\
-\end{array}$ & $\begin{array}{l}+ \\
+(\text { proximal) } \\
+ \\
+ \\
+\end{array}$ \\
\hline Prognosis & Fatal & Good & Fatal \\
\hline Genetic transmission & $\begin{array}{c}\text { autosomal } \\
\text { dominant-sporadic }\end{array}$ & Sporadic & $\begin{array}{l}\text { autosomal } \\
\text { recessive } \\
\text { dominant? }\end{array}$ \\
\hline Diagnosed age & $30-40$ & $30-40$ & $10-40$ \\
\hline \multicolumn{4}{|l|}{ Urogram } \\
\hline $\begin{array}{l}\text { I.V.P. } \\
\text { Retrograde P. } \\
\text { Angiogram }\end{array}$ & $\begin{array}{c}\text { occasionally } \\
\text { invisuable } \\
\text { pelvocalcyeal defects } \\
\text { large cysts }\end{array}$ & $\begin{array}{l}\text { pyramidal } \\
\text { opacification } \\
\text { normal. } \\
\text { normal }\end{array}$ & $\begin{array}{l}\text { occasionally } \\
\text { invisuable } \\
\text { normal } \\
\text { small cysts }\end{array}$ \\
\hline \multicolumn{4}{|l|}{ Pathological changes } \\
\hline $\begin{array}{l}\text { Cortex } \\
\text { Medulla }\end{array}$ & $\begin{array}{l}\text { cysts } \\
\text { cysts }\end{array}$ & $\begin{array}{l}\text { normal } \\
\text { ectasia }\end{array}$ & $\begin{array}{l}\text { fibrosis } \\
\text { cysts }\end{array}$ \\
\hline
\end{tabular}


maturia. Moreover, retrograde pyelogram shows pelvocalceal defects in polycystic kidney, while in medullary cystic disease it shows normal appearances, as seen in this patient. Medullary sponge kidney should be differentiated from medullary cystic disease because they are different diseases, although in the past they have been confused with each other. The main differences are in the course of the disease, and the fact that the cysts in medullary cystic disease are at the corticomedullary junction, while those in sponge kidney are in the collecting tubules and are at the tips of the papillae. Most sponge kidney is not inherited and follows a benign course if uncomplicated. The diagnosis usually can be made by intravenous pyelography, on the basis of mildly dilated tubules and/or the clusters of small calculi in the renal papillae ${ }^{8}$.

Medullary cystic disease is often not recognized until azotemia and anemia appears, because the early warning signs of renal disease, such as hypertension, hematuria, and abnormal urinary sediment are absent ${ }^{1-4)}$. Therefore, it might be impossible to obtain a useful intravenous pyelogram in any $\mathrm{case}^{9)}$, since these patients are always uremic when first seen. However, it is necessary for a clinician to make a diagnosis and begin the treatment for osteodystrophy, acidosis and dehydration, as early as possible. Recently, Mena et $\mathrm{al}^{10)}$ reported that angiographic features in this disorder were specific and enabled differentiation from other conditions, such as sponge kidney, classical polycrstic kidney and pyelonephritis. In 4 of 5 cases, cystic changes were radiologically seen. In addition, the peripheral cortical margins of the cysts were intact, while there was cortical interruption of cysts in polycystic kidney. In this patient, the correct angiographic diagnosis could be suggested on the basis of cystic changes and the lack of cortical interruption (Fig. 2, 3). Therefore, renal angiography may offer a safer and equally satisfactory approach in patients with me- dully cystic disease, even if they are uremic. Herdman et al demonstrated such signs of distal damage as reduced ability to concentrate and acidify the urine but the absence of glycosuria and aminoaciduria, concluding that the proximal tubule was not affected in medullary cystic disease ${ }^{3)}$. However, our patient was associated with hyperchloremic metabolic acidosis, hypokalemia, and hyperreninemia, which could be explained as a consequence of proximal renal tubular acidosis (proximal RTA). Because renal potassium wasting became more severe when acidosis was corrected with a large amount of alkali, although in distal RTA correction of acidosis is predictably attended by a reduction in the urinary excretion rate of potassium ${ }^{11}$. In addition, the observation supported the presence of proximal RTA in this patient that the urinary $\mathrm{pH}$ was further increased to 8.1 when plasma $\mathrm{pH}$ became normal with the alkali ${ }^{12)}$. In this disorder of renal acidification, the impairment of becarbonate reabsorption in the proximal tubule results not only in bicarbonate wasting, leading to hyperchloremic "alkali-resistant" acidosis, but in delivery to the distal tubules of such increased amounts of the relative impermeant bicarbonate anion that distal intraluminal electronegativity is increased, potassium secretion is thereby increased, and renal potassium wasting is promoted $^{11)}$. In addition, hypokalemia is partly due to secondary aldosteronism. He was associated with high plasma renin activity, hyperaldosteronism, and juxtaglomerular cell hyperplasia. These conditions might be caused from the depressed extracellular volume, because of the tendency of salt-wasting, which is apparently similar to the pathophysiology of Bartter's syndrome $^{18,19)}$ (Fig. 2). The causes of renal osteodystrophy in this patient were not only renal failure but also proximal tubular dysfunction. Especially, osteomalacia is often found in medullary cystic disease, which may be due to the impaired reabsorption of phosphate and bicarbonate, via 
hypophosphatemia and acidosis. Recently, it has become well known that in the kidney, particularly in the proximal tubular cells, vitamin $\mathrm{D}$ is activated by $1 \alpha$ hydroxylase and that 1,25-dihydroxycholecalciferol, an active vitamin $\mathrm{D}$ metabolite, is produced ${ }^{20)}$. Since the deficiency of 1,25 dihydroxycholecalciferol may cause osteomalacia ${ }^{21}$, it should be considered as a cause of osteodystrophy in this patient.

In this patient, as well as patients reported by Giselson et $\mathrm{al}^{13)}$, additional evidences of proximal tubular dysfunction were found such as glycosuria, lysozymuria and hyperuricosuria. Since lysozyme is a low-molecular-weight protein, it is freely filtered at the glomeruli and reabsorbed by the proximal tubule. Therefore, normally the urine contains its trace amounts. Increased excretion of lysozyme has been demonstrated in patients with proximal tubular damages such as cadmium poisoning ${ }^{14,15)}$. Most recently, we have reported that injection of maleic acid in the rats produced experimental Fanconi syndrome associated with massive lysozymuria ${ }^{25)}$. However, in the azotemic patients, serum lysozyme is increased and then lysozymuria can result from filtered loads of lysozyme exceeding the maximum transport capacity of the proximal tubule.
Since the fractional absorption of lysozyme is relatively constant over a wide range of plasma concentrations, we have measured the fractional lysozyme clearance. Consequently, the value in this patient is significantly higher than in chronic glomerulonephritis, and equal to that of Fanconi's syndrome which is a typical disease causing proximal RTA. Evidence presented suggests that the patient with medullary cystic disease is associated with proximal tubular dysfunction.

The pathogenesis of this disease remains obscure. Mongeau et al have suggested that medullary cystic disease results from the action on the kidney of a nephrotoxic substance, which accumulates because of an inborn metabolic error ${ }^{22)}$. Their suggestion has some basis in the experimental fact that rats fed diphenylamine develop medullary cysts in their kidney ${ }^{23,21)}$. It is well known that most patients with chronic intoxication of a heavy metal e.g. cadmium or lead, might suffer from proximal tubular dysfunction, prior to the disturbance of glomerular function ${ }^{15}$. The course of this disorder with tubular damage early and silent progression to renal insufficiency is similar to that seen in a number of toxic nephropathies. Moreover, the resemblance to toxic nephropathy is also seen in the

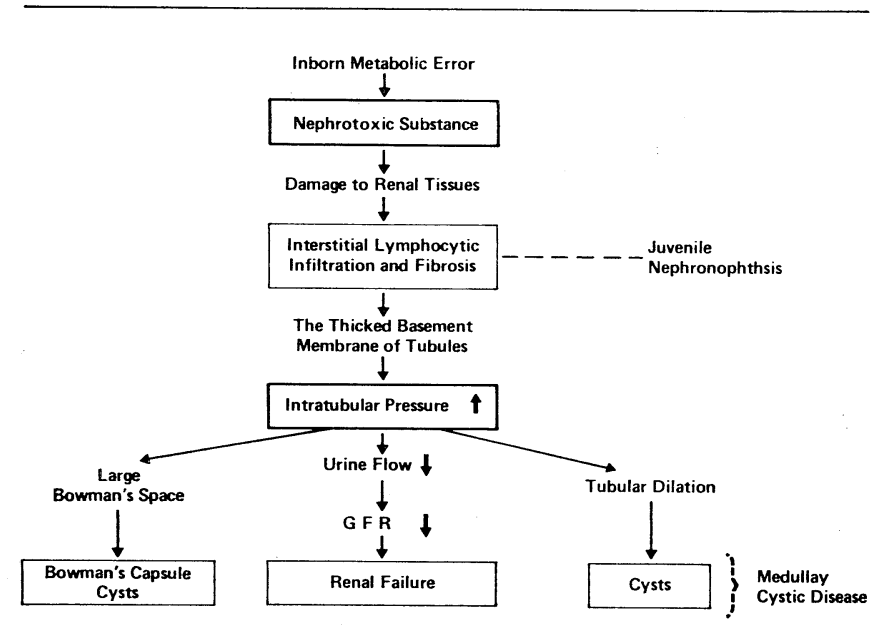

Fig. 7. The pathogenesis of medullary cystic disease and juvenile nephronophthisii. 
appearance of the kidney. In this patient, as reported in most cases of medullary systic disease, the basement membrane of some tubules was concentrically thickened, forming a collar around the tubules. Some tubules were dilated and a large Bowman's space was present around the glomeruli (Fig. 5). Evidence presented suggests that the development of the cysts is a secondary process in which a localized thickening of the basement membrane leads to partial obstruction of the urine flow in a nephron with well functioning glomerulus, in turn a rise in intratubular pressure resulting in cystic dilatation of the tubule, leading to tubular dysfunction, and in a large Bowman's space (Fig. 7). As a result, juvenile nephronophthisis is the early state that cysts are not yet developed, probably progressing to medullary cystic disease. Therefore, it seems to be an attractive theory that a toxin, causing damage to renal tissue, accumulates because of a metabolic error in medullary cystic disease, although any nephrotoxic substance has not been identified.

\section{REFERENCES}

1) Smith $\mathrm{CH}$, Graham JB: Congenital medullary cysts of the kidneys with severe refractory anemia. Am J Dis Child 69: 369, 1945.

2) Strauss MB: Clinical and pathological aspects of cystic disease of the renal medulla: an analysis of sixteen cases. Ann Int Med 52: 393, 1962.

3) Herdman RC, Good RA, Vernier RC: Medullary cystic disease in two siblings. Am J Med 43: 335, 1967.

4) Goldman $\mathrm{SH}$ et al: Hereditary occurence of cystic disease of the renal medulla. N Eng J Med 274 : 948, 1966.

5) Fanconi $G$ et al: Die familiare juvenile Nephronophthise. Helv Paediatr Acta 6: $1,1951$.

6) Winberg $\mathrm{J}$ : Correspondence. Am J Dis Child 108 : 556, 1964.

7) Strauss BM, Sommers SG: Medullary cystic disease and familial nephronophthisis. Am J Med 43 : 335, 1967.

8) Spence HM, Singleton $R$ : What is sponge kidney disease and where does it fit in the spectrom of cystic disorders? J Urol 107: $176,1972$.

9) Spicer RD et al: Renal medullary cystic disease. Birt Med J 1: 824, 1969.

10) Mena $E$ et al: Angiographic findings in renal medullary cystic disease. Radiology 110: 277, 1974.

11) Morris RC Jr et al: Renal acidosis. Kid Int 1: 322, 1972.

12) Fujita $T$ et al: Hypergammaglobulinemic renal tubular acidosis. JAMA 234: 742, 1975.

13) Giselson $\mathrm{N}$ et al: Renal medullary medullary cystic disease or familial juvenile nephronophthisis-A renal tubular diesase. Am J med 48 : 174, 1970.

14) Prockop DJ, Davidsson WD: A study of urinary and serum lysozyme in patients with renal disease. N Eng J Med 270: 269, 1964.

15) Saito $\mathrm{H}$ et all: Chronic cadium poisoning induced by environmental cadmium pollution. Jap J Med 16: 2, 1977.

16) Kobayashi A et al: Familial juvenile nephronophthisis-Report of cases in two siblings. Acta Paed Jap 9: 1, 1967.

17) Osserman E, Lawlow DP: Serum and urinary lysozyme (muramidase) in monocytic and monomyelocytic leukemia. J Exp Med 124 : 921, 1966.

18) White MG: Bartter's syndrome, a manifestation of renal defects. Arch Int med $129: 41,1972$.

19) Fujita $T$ et al: The pathogenesis of Bartter's syndrome. Functional and histologic studies. Am J Med 63: 487, 1977.

20) Editorial: Regulation of vitamin D metabolism. Nature 245: 180, 1973.

21) Jowsey J: Calcium release form the skeletone of rachitic pappies. J Clin Invest 51: 9, 1972.

22) Mongeau JG, Worthen HG: Nephronophthisis and medullary cystic disease. Am J Med 43 : 345, 1967.

23) Kime SW Jr, McNamara JJ et al: Experimental polycystic renal disease in rats. Electron microscopy, function and susceptibility to pyelonephritis. J Lab Clin Med $60: 64,1962$.

24) Eknoyan GD et al: Renal function in experimental cyctic disease of the rat. J Lab Clin Med 88: 402, 1976.

25) Fujita $T$, Itakura $M$ : Renal handling of lysozyme in experimental Fanconi Syndrome. J Lab Glin Med 92: 135, 1978. 